\title{
POESÍA POPULAR CHILENA: IMAGINARIOS Y MESTIZAJES CULTURALES
}

\author{
POPULAR CHILEAN POETRY: IMAGINARIES \\ AND CULTURAL MESTIZAJES
}

\section{MARISOL FACUSE M. ${ }^{1}$}

\section{RESUMEN}

El presente artículo busca analizar los imaginarios que circulan en la poesía popular chilena a la luz del concepto de mestizaje cultural propuesto por François Laplantine y Alexis Nouss. Considerando las múltiples herencias de este arte practicado en América Latina desde la época colonial, así como las sucesivas reapropiaciones de las cuales ha sido objeto, se profundizará en el imaginario puesto en escena por los poetas populares en el presente. A partir de un trabajo de observación directa de diversos encuentros de payadores en Chile, se tendrán en cuenta distintas dimensiones para el análisis: imaginario sonoro (voz, instrumentos musicales), teatralidad (tipos de escenificación, lugares de espectáculo, relación con el público), textualidad (contenidos, personajes, situaciones evocadas), a fin de aprehender la complejidad de este fenómeno artístico, asumiéndolo como un "hecho social total".

Palabras clave: Poesía popular, mestizaje cultural, imaginario, culturas populares.

\section{ABSTRACT}

This article seeks to analyse the imaginaries that are featured in popular Chilean poetry in the light of the concept of cross-cultural mixing ("mestizaje") put forward by François Laplantine and Alexis Nouss. By considering the various legacies of this art as practised in Latin America since the colonial era, as well as the successive re-appropriations of which they have been object, we will probe into the imaginary staged by the popular poets of the present. Starting from direct observational work of various encounters

1 Doctora en Sociología Universidad Pierre Mendès-France, Grenoble II. Académica Departamento de Sociología, Facultad de Ciencias Sociales, Universidad de Chile. Santiago, Chile. E-mail: marisolfacuse@uchile.cl 
of popular singers ("payadores") in Chile, several dimensions will be taken into account in the analysis: sound imaginary (voice, musical instruments), theatrical (types of staging, places of the spectacle, relation with the audience) and textuality (contents, characters, invoked situations), in order to comprehend the complexity of this artistic phenomenon, to approach it as a "whole social event".

Keywords: Popular poetry, cross-cultural mixing, imaginary, popular arts.

Recibido: 04.11.10. Aceptado: 20.04.11.

\section{POESÍA POPULAR Y MESTIZAJE CULTURAL EN EL CONTEXTO LATINOAMERICANO}

I

A POESÍA popular en América Latina es el resultado de un sinnúmero de cruces e influencias cuyo ejercicio genealógico sabría difícilmente detenerse en un punto preciso. La poesía arabo-andaluza, el romancero español, el arte de los juglares y trovadores medievales, la religiosidad popular, entre muchas otras fuentes, han dado la materia a esta particular forma artística, que ha sido cultivada en nuestro continente desde la época colonial. Sin embargo, a pesar de su larga data, lejos de constituirse en la repetición inmóvil de una época remota, la poesía popular ha sido objeto de múltiples reapropiaciones, transformándose de acuerdo a la diversidad de las culturas musicales de nuestro continente.

Es así que podemos escuchar hablar de "repentismo", "punto cubano" o "paya", para hacer referencia a un mismo fenómeno poético/musical, en el cual a partir de una estructura métrica común, el verso espinel, se despliegan diversas posibilidades creativas a través de la oralidad y la improvisación. En América Latina y el Caribe la estructura de la décima se ha ido acoplando a los diferentes ritmos, instrumentos musicales y formas de interpretación vocal, dando lugar a resultados muy distintos en el plano musical y escénico en acuerdo a las tradiciones artísticas y a los contextos socio-históricos de cada región.

En las múltiples genealogías realizadas sobre la poesía popular existe un relativo consenso en torno a la figura de Vicente Espinel (1550-1642) como el autor de la estructura métrica que la caracteriza en el mundo hispanoparlante desde el siglo XVI. Sin embargo, según Rodolfo Lenz (2003), dicha forma habría preexistido al poeta español, cuyo rol habría sido más bien el de darla a conocer a través de sus composiciones. En ambos casos la referencia permite comprender la apelación aún vigente de "verso espinel" 
o "décima espinela" para hacer referencia a un tipo de verso octosilábico, cuya rima es: Aabbaaccddc. Su estructura se organiza a partir de una cuarteta seguida de cuatro décimas que deben finalizar con el verso correspondiente a la cuarteta en el mismo orden de disposición. Los poetas chilenos agregaron una última estrofa de "despedida" que sirve de clausura, la cual es conocida por los poetas populares como "remate".

La multiplicidad de fuentes de esta forma artística y sus posteriores mutaciones estéticas y temáticas, así como sus transformaciones en el espacio social, nos permiten pensarla bajo el prisma del mestizaje cultural tal como es propuesto por François Laplantine y Alexis Nouss (2007). La noción es utilizada por los autores para analizar fenómenos tan diversos como el hiphop, el jazz, el postcolonialismo o la literatura de Pérec. El mestizaje, nos dirán los autores, es el resultado del trabajo del tiempo y de lo múltiple, oponiéndose a los valores hegemónicos dominantes de la identidad, de la estabilidad y de la anterioridad (Laplantine y Nouss, 2008, p. 8).

Buscando distinguir esta noción de los conceptos de hibridez o de sincretismo, los autores insisten en el hecho de que una comprensión errada del mestizaje implicaría: "la existencia de dos individuos originalmente 'puros' o en un estado inicial -racial, social, cultural, lingüístico-, de un conjunto homogéneo que en algún momento habría encontrado otro conjunto, dando vida a un fenómeno 'impuro' o 'heterogéneo'” (Laplantine y Nouss, 2008, p. 8). Precisamente la noción de mestizaje viene a contradecir el binomio homogéneo/heterogéneo, pues se trata de una composición en la que las dos partes preservan su integridad (Laplantine y Nouss, 2008, p. 8). Esta comprensión nos acerca a la reflexión propuesta por Ticio Escobar a propósito del arte intercultural en América Latina, caracterizado por las apropiaciones realizadas por las culturas periféricas de las imágenes y los discursos propuestos por las culturas centrales (Escobar, 2008).

El concepto de mestizaje nos aparece prolífero para aportar a la comprensión de la poesía popular en el contexto chileno, respondiendo con ello a la necesidad de renovar las grillas de análisis para abordar un fenómeno estudiado mayoritariamente bajo el prisma de los estudios folclóricos. Buscaremos así contrastar un enfoque que ha observado "las músicas del pueblo" únicamente en su relación con la tradición, valorizándolas a partir de un cierto ideal purista y homogéneo. Contrariamente, sostendremos que la poesía popular puede ser pensada como una forma de mestizaje cultural en la que se cruzan diversas fuentes a la vez cultas y populares, religiosas y profanas, para nutrir un género en constante reinvención. 


\section{LA POESÍA POPULAR COMO UN MUNDO DEL ARTE}

Una mirada sobre la actualidad de la poesía popular en nuestro país nos permitirá constatar este doble movimiento de continuidad y de reapropiación en relación a los primeros cultivadores del género en la época colonial.

La decisión de situar nuestro estudio en la época presente busca evitar el riesgo de una eventual museificación a partir de la cual se observa la poesía popular como una práctica en extinción o bien como un fenómeno del pasado, una tendencia que ha sido evocada en recientes investigaciones (Chaparro, 2010). Sin embargo, a pesar de su limitada presencia en el interés de los investigadores(as) y de los medios de comunicación masivos, la poesía popular sigue siendo practicada en diversas regiones de nuestro país a través del trabajo creador de poetas de distintas generaciones, orígenes sociales y geográficos, convocando a un número considerable de público. Por ello, sin ignorar la necesidad de estudiar el fenómeno desde una perspectiva histórica, nos interesaremos por conocer cuáles son los espacios sociales de inscripción de esta práctica artística en la actualidad.

Para cumplir con este objetivo hemos observado la producción artística de los poetas populares, comprendiéndola como un "mundo del arte" en plena actividad en el sentido propuesto por H. S. Becker (2008). El concepto de mundo del arte nos invita a comprender la creación artística como un proceso que implica la participación de una red de múltiples actores (creadores, técnicos, instituciones culturales, críticos de arte, medias, públicos, etc.), cada uno de los cuales constituye un eslabón en la "cadena de producción" de las obras. Los artistas y las tareas relacionados con la creación tienen a partir de este modelo de análisis una función importante, pero no exclusiva, para llegar al resultado final. La sociología encuentra su pertinencia aquí estudiando las formas de organización social del trabajo artístico y su relación con otras esferas de la vida social (institucional, política, económica, simbólica, etc.).

La metodología empleada para la construcción del corpus ha sido de tipo etnográfica, privilegiando la observación directa de diversos encuentros de poesía popular en la zona central de nuestro país: Casablanca (V Región), Portezuelo (VIII Región), Pirque y Santiago (RM). La observación se ha complementado con entrevistas en profundidad a poetas populares de diferentes regiones del país, teniendo en cuenta igualmente la reflexión de otros actores relacionados con el mundo de la poesía popular : organizadores de encuentros, animadores, públicos. Siguiendo a Clifford Geertz (1992), a través del método etnográfico, hemos intentado "trazar la curva 
de un discurso social" el de la poesía popular, buscando comprender las significaciones que los propios actores otorgan a este arte en la actualidad.

\section{LA POESÍA POPULAR CHILENA: DIMENSIONES DE UN MESTIZAJE}

Retomando la hipótesis central de este artículo, afirmaremos que la poesía popular chilena tal como es practicada en el presente, testimonia diversos procesos de mestizaje cultural que refieren tanto a aspectos estéticos (musicalidad, teatralidad), como a las sociabilidades y a los imaginarios movilizados. La observación in situ de su puesta en escena y el intercambio con los poetas acerca de su quehacer nos ha permitido distinguir algunos ejes en los que es posible reconocer estos procesos. El análisis en profundidad de esta forma artística evidencia cómo en este arte se tensionan algunas de las categorías a partir de las cuales se organizan los mundos del arte institucionales (culto y popular, divino y profano, profesional y amateur, etc.). Como hemos anunciado más arriba, en la puesta en escena de esta forma poético-musical muchas de estas categorías aparecen reconfiguradas y las propias fronteras entre los géneros artísticos se vuelven porosas.

La noción del mestizaje tal como la hemos asumido nos reenvía a la controvertida cuestión de las filiaciones y de los orígenes, cuya coherencia deberá siempre ser observada a la luz de su condición hipotética e incluso ficcional. Como lo señalan los autores de la teoría del mestizaje: "La circulación (de hombres, de animales, de plantas, de técnicas, de religiones de símbolos) es tan intensa que al final deviene difícil discernir 'elementos' o 'influencias' en su estado puro" (Laplantine y Nouss, 2008, p. 18). Así, la pregunta por los orígenes de la poesía popular nos reenvía a las múltiples herencias culturales de nuestro continente contrarias a la ficción de pureza y unidad vehiculada históricamente por el proyecto colonizador.

\section{Voz, imaginario sonoro y mestizaje de géneros}

Catherine Dutheil-Pessin, interrogándose acerca de las posibilidades heurísticas de la canción como un objeto de investigación, nos recuerda el carácter dual de la voz cantada, afirmando su naturaleza mixta entre la carne y el mundo, entre sí y el otro, entre mundo interior y mundo exterior. Para la autora, en un régimen en donde predomina un imperialismo de lo escrito, la canción vendría a operar como una "oralidad viva". 
La voz cantada es capaz de vincular la memoria, los mitos individuales y los mitos colectivos, creando una trama permanente entre mito e historia, por lo cual constituye un lugar privilegiado para leer la profundidad de una cultura o de un momento histórico (Dutheil-Pessin, 2004, pp. 18 y 35). En consecuencia, la canción debe ser estudiada como un "espectáculo vivo", como un arte de la escena considerando para ello el cuerpo del artista, los contenidos musicales, las emociones y las significaciones compartidas que reenvían a un imaginario común (Dutheil-Pessin, 2004, p. 40).

En la denominación utilizada por los poetas chilenos para reconocer su arte, "Canto a lo poeta", podemos advertir esta ambivalencia de la voz cantada. Haciendo alusión al carácter fronterizo de esta forma, la voz de los cantores a lo poeta se sitúa a la interfase del canto y la recitación. En efecto se trata de una poesía cantada, cercana a la salmodia, un canto poético cuya dinámica vocal sabe combinar poesía y canción. Las voces populares según Dutheil-Pessin poseerían su propio modo de expulsión de la voz, caracterizado por una manera no académica de utilizar el resonador. A diferencia de las voces del canto lírico, esta modalidad se relaciona con el espacio donde estas voces fueron moduladas a partir de entonaciones, ritmos y formas de proyectar la voz propios del habla popular: "Las voces habitan los lugares, los hacen vibrar, los hace existir, pero los lugares también habitan las voces, que guardan sus trazos" (Dutheil-Pessin, 2004, p. 73, traducción de la autora).

El universo simbólico puesto en escena por los cantores a lo poeta es habitado simultáneamente por distintas épocas y lugares. Su voz cantada posee un timbre particular y un "grano de voz" que evocan el habla campesina y popular, portando en su imaginario sonoro los trazos de existencias y de historias, por lo general ausentes de la memoria oficial. Pregones, refranes, rezos, juegos, antiguos oficios, se cristalizan en esta particular estética de la voz cantada.

En lo que respecta a los instrumentos de acompañamiento, el que predomina en el canto a lo poeta es el guitarrón chileno de veinticinco cuerdas. A pesar de no ser el instrumento exclusivo que ha acompañado y que acompaña aún el canto a lo poeta, el guitarrón es considerado por poetas e investigadores, el instrumento propio de esta forma poética/musical. Al referirse a sus orígenes y a sus posteriores metamorfosis, el investigador y cantor a lo poeta Moisés Chaparro establece una filiación directa de este instrumento con la tradición hispánica de la guitarra, del cual sin embargo se distancia debido a la complejidad de su encordado y las combinaciones musicales resultantes (Chaparro 2010, p. 108). Al mismo tiempo su sonido 
y su forma reenvían al laúd, testimoniando las múltiples herencias musicales y culturales que resuenan en este particular imaginario sonoro.

Haciendo referencia a los trabajos del investigador chileno José Pérez de Arce, Chaparro nos recuerda que el guitarrón es el resultado de la infinita variedad de instrumentos que llegados de la tradición hispánica se desarrollan en América Latina: "La desigual cantidad de cuerdas de diferentes órdenes para un mismo instrumento, la combinación de tripa y metal y las tonalidades octavadas, estarían ligadas con los laúdes y archilaúdes del Renacimiento europeo y la guitarra renacentista española" (Chaparro, 2010, p. 109).

Voces e instrumentos en la poesía popular reenvían a una multiplicidad de imaginarios sonoros (arabo-andaluz, hispánico, campesino, etc.), actualizando los múltiples cruces y mestizajes culturales de los que este arte ha sido objeto. Diversas temporalidades y territorios se activan en su puesta en escena contemporánea a través del trabajo creador de los artistas populares.

\section{Lo divino y lo humano en la poesía popular}

El imaginario sonoro de la poesía popular nos permite abordar otra de las dimensiones del mestizaje de esta forma artística, relacionada con la distinción -que se vuelve a la vez continuidad- entre el Canto a lo Divino del Canto a lo Humano. La diferencia está dada por los temas tratados, pero también por la función social de cada una de estas formas. Rodolfo Lenz (2003) en su descripción de la poesía impresa de fines del siglo XIX en Chile da cuenta de la existencia de estas dos modalidades de la poesía popular presente en el arte de sus primeros cultores.

En la actualidad una buena parte de los poetas cultivan ambas formas, siendo frecuente el hecho de haberse iniciado desde niños en las ruedas de Canto a lo Divino como espectadores para más tarde devenir cantores. El contenido de los versos está dado por relatos provenientes de la tradición oral, basados en el texto bíblico que son recolectados, memorizados y transmitidos de unos cantores a otros. Las ruedas de Canto a lo Divino tienen lugar en el contexto de vigilias organizadas en diferentes localidades de la zona central. Muchas de ellas se organizan en torno a fechas relacionadas con los llamados "santos patronos".

Aquí la poesía toma la forma de una oración cantada tal como lo explica uno de los payadores entrevistados: 


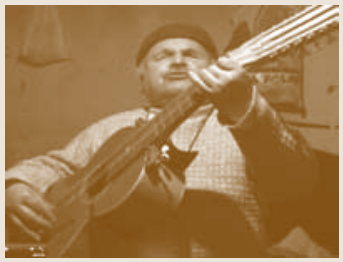

S. Rubio el Canto a lo Divino son verdaderas oraciones si se quisiera decir, y de ahí que viene que "el que canta reza dos veces" es como un dicho, una forma de darle la connotación que el canto se merece, entonces en esas vigilias de Canto a lo Divino se trasnocha porque empieza la rueda de canto mas menos a las ocho de la noche y termina al otro día entre las seis y las siete de la mañana, se canta toda la noche (Antonio Contreras, Torito, payador).

El Canto a lo Divino y el Canto a lo Humano están íntimamente ligados, lo que se expresa en una creencia ampliamente difundida entre los poetas según la cual "un día nació el Canto a lo Divino y al día siguiente nació el Canto a lo Humano".

En efecto, si bien cada una de estas formas posee su propia estructura y sus particulares tipos de escenificación, a menudo ambas modalidades son practicadas en los encuentros de poesía popular, donde es común que los poetas cultiven ambos registros.

Esta vecindad entre las esferas de lo humano y lo divino puede traducirse igualmente en los contenidos de la poesía cantada en que algunos versos pueden transmutar de una modalidad a otra, creando una transversalidad entre ambas experiencias. El mismo poeta entrevistado da cuenta de este tránsito de un registro al otro a través de un ejemplo en que una cuarteta proveniente del Canto a lo Humano es glosada en Canto a lo Divino. La intención abiertamente picaresca de la cuarteta revierte su sentido adoptando el fundamento de "canto por nacimiento de Cristo":

Una mujer lo tenía todo cubierto de pelo, yo lo probé y era bueno a la hora de mediodía

Antes que aclarara el día y el sol nos diera sus pasos, el niño Jesús en brazos una mujer lo tenía

Jesús, María y José sentían un gran consuelo, lo cuidaban con anhelo y sentían gran contento, y el buey le echaba el aliento todo cubierto de pelo 
Esta proximidad que puede volverse fusión entre lo divino y lo humano, aparece como uno de los componentes del mestizaje presentes en la poesía popular. El historiador Maximiliano Salinas (2005) analiza esta contigüidad entre devoción y erotismo presente en la religiosidad popular chilena en la sociedad del siglo XIX. Para el autor la actitud que él reconoce como "amorosa" propia de la religiosidad popular, se expresa en las maneras de nombrar y de dirigirse a la divinidad y a la Virgen María. Se trata de una forma de vivir lo religioso que sabía combinar "lo maravilloso y lo orgiástico" en una indisoluble unidad (Salinas, 2005, p. 26). Eclipsada por la religión oficial de los grupos dominantes, esta forma de comprender y vivir la creencia religiosa se vuelve marginal en favor de la cultura eclesiástica postridentina: "un tipo de religiosidad elitista, que acentúa los rasgos jerárquicos, paternalistas de autoridad" (Salinas, 2005, p. 313). El nuevo orden religioso re-trazaba de manera irreconciliable los dominios de lo sagrado y lo profano. No obstante, como hemos visto el imaginario que fusiona estos dos ámbitos no desaparece completamente sino que sigue circulando a través de soportes tales como las formas de arte popular.

\section{Artistas y espectadores: Un público creador}

Otro ámbito en donde se hace presente el mestizaje en la poesía popular se relaciona con el lugar del espectador, el que cobra una particular relevancia en los encuentros de poesía improvisada. El proceso creativo que tiene lugar durante el espectáculo resulta del trabajo elaborado por los artistas in situ a partir de los contenidos propuestos por los espectadores. En dichos eventos, los cantores solicitan al público que proponga versos (llamados "pies" en la jerga de los poetas populares), relativos a temas, preguntas o personajes, que deben irse incorporando a las décimas de acuerdo a las distintas modalidades (pie forzado, banquillo, ovillejo, personificación, etc.). Con ello queda demostrado el carácter improvisado de los versos y los cantores dan prueba de su agilidad y destreza para manejar simultáneamente el lenguaje, la métrica y las complejas convenciones de la décima espinela. El espectáculo es así el resultado de una fuerte interacción entre los artistas y el público, pudiendo este último marcar el tenor, nivel de exigencia y temáticas abordadas por los cantores en cada encuentro.

Los temas y personajes propuestos por el público son re-trabajados por los poetas en la escena, reactivando un imaginario y una memoria colectivas. Es frecuente que el público proponga temas relacionados con la actua- 
lidad política y su contingencia, lo que obliga a los artistas a posicionarse sobre el tiempo presente y sus tensiones. Los poetas populares devienen así intérpretes de su tiempo, actualizando luchas sociales y conflictos a partir de una particular "poética de lo político".

El público se vuelve co-partícipe del proceso creativo y del resultado final del espectáculo, produciéndose una fusión de los límites que separan a los artistas y a los espectadores. Los espectadores entrevistados en los encuentros de poesía popular hacen alusión a esta relación de intensa proximidad con los poetas, la que suele proyectarse más allá del espectáculo, tal como da cuenta el siguiente testimonio:

el payador es un artista, pero lo siento mucho más cercano, de hecho eso es lo que me agrada de cuando vengo aquí a Portezuelo porque yo sé que en algún minuto, o yo con mis grados de alcohol, o él con su simpatía, se acercará, nos conoceremos y hablaré con él, me dará cinco minutos para presentarle a mi familia y después podrá él seguir conversando (espectador Encuentro de poetas populares de Portezuelo, 2010).

La práctica de la poesía improvisada involucra a artistas y espectadores en sus procesos de creación y escenificación. Los poetas populares ponen en escena una particular comprensión del arte y de los artistas en la que se funden públicos y cantores para en definitiva acortar las distancias entre la temporalidad del espectáculo y la temporalidad cotidiana, entre el arte y la vida.

La relación que establecen los espectadores con el arte de los payadores puede ser pensada en términos de una heterología que según Alexis Nouss está en directa relación con el mestizaje: "El mestizaje alimenta una atención constante y sostenida hacia los otros, fuera de sí y en sí. Por esta razón puede ser definido como heterología" (Laplantine y Nouss, 2007, p. 365). Evocando la obra de Michel de Certeau, los autores del mestizaje ven en la heterología una crítica al concepto de identidad plena y unificada a favor de la fragmentación a la vez del ser y del saber: "Aquí la alteridad ya no se plantea en el exterior sino que trabaja la unidad interna del ser o el saber. Esta crítica es relevada en la actualidad por pensadores que plantean sus incidencias sociopolíticas (feminismo o poscolonialismo). De Certeau la conduce sobre el frente ontológico, religioso, sobre aquél, sociológico, de la cultura. En ambos casos lo que se combate es lo homogéneo, en nombre del pluralismo y de la creatividad individual como formas de resistencia" (Laplantine y Nouss, 2007, p. 366).

El arte de los payadores es "heterológico" en cuanto al descentramiento 
que propone para la nociones de autor y de artista. La noción de autor, tributaria de la idea moderna del artista, es aquí puesta en juego para dejar de centrarse únicamente en un sujeto individual y convertirse en una palabra colectiva. Esta desmultiplicación del autor tendrá su eco también en la noción del saber de una sociedad, que ya no provendrá de un único lugar hegemónico (individual, patriarcal, colonial) sino que será el resultado de una o varias interpretaciones del mundo elaboradas colectivamente.

Los autores del mestizaje nos recuerdan que la heterología se relaciona con la dimensión dialógica, relevada por Bajtín a propósito de la novela. Se trata de un aspecto que aparece como constitutivo de la poesía popular, el que puede experimentarse en distintos niveles: diálogo entre los poetas, entre éstos con el público, entre la obra y la experiencia colectiva. En efecto es usual escuchar de boca de los cantores populares, la referencia al origen quechua de la palabra "paya" que querría decir "dos", para dar cuenta de la importancia del diálogo y el intercambio en este arte. Son también frecuentes entre los cantores las denominaciones de "diálogo poético" o "desafío poético", las que dejan en evidencia la modalidad dialógica de esta puesta en escena. Este diálogo, iniciado en la escena por los poetas, adquiere una cierta fractalidad, al convertirse en diálogo de los artistas con el público, y de éstos con un presente y una memoria colectiva. Artistas y públicos participan en una dinámica social de creación a través de la cual se va reelaborando colectivamente la realidad.

Siguiendo a los autores del mestizaje podemos relacionar esta dimensión dialógica con la búsqueda de la alteridad: "La pulsión que anima este diálogo no es otra que la alteridad, en dos niveles: por un lado, el enfrentamiento entre el 'yo' y el 'otro' y, por el otro, la senda desgarrada de cada uno" (Laplantine y Nouss, 2007, p. 368). Así podríamos decir que en la poesía popular "toda voz es la voz del otro".

\section{CONCLUSIONES}

Este periplo por las múltiples dimensiones de la poesía popular y sus relaciones con el mestizaje nos abre a una serie de otras posibilidades de análisis. Los tres ejes que hemos desarrollado aquí constituyen sólo algunos ejemplos de cómo el estudio en profundidad de esta forma poético/musical nos permite abordar aspectos relativos a nuestra cultura y a nuestros "modos de hacer colectivos" (De Certeau, 1990). La exploración de estas dimensiones nos muestra que se trata de una forma en la que a menudo 
son subvertidas las categorías que organizan los mundos del arte institucionales en favor de nuevas configuraciones. Estos efectos de ruptura pueden ser analizados tanto en el dominio interno (voz, musicalidad, teatralidad, contenidos) como externo (modos de circulación, relación con el público, etc.) de la producción artística. Los resultados presentados nos convocan a continuar profundizando en esta vía de análisis, incorporando nuevas dimensiones que recorren en gran medida los ejes aquí tratados. Las fronteras que separan al arte moderno del arte tradicional, el culto y el popular, el amateur y el profesional, o la cultura urbana de la rural, pueden ser repensadas a partir de la comprensión de esta práctica artística en el presente. A su vez la desjerarquización de estas categorías nos abre a una reflexión más general sobre los procesos de mestizaje cultural y su relación con las controvertidas temáticas de la identidad y la alteridad en nuestro continente.

\section{REFERENCIAS}

Becker, Howard (2008). Los mundos del arte. Argentina: Ed. Universidad Nacional de Quilmes.

Chaparro, Moisés (2010). El payador chileno a comienzos del siglo XXI. Santiago de Chile: Tesis para optar al grado de Magíster en Políticas Sociales y Gestión Local, Universidad Arcis.

De Certeau, Michel (1990). L'invention du quotidien, 1. arts de faire. París, Francia: Gallimard.

De Certeau, Michel (1993). La culture au pluriel. París, Francia: Du Seuil.

Dutheil Pessin, Catherine. (2004) La chanson réaliste. Sociologie d'un genre. París, Francia: L'Harmattan.

Escobar, Ticio (2008). A propósito de un arte híbrido e intercultural. Disponible en Internet: http://web.mac.com/susalerno/CAVMdB/textos/Entradas/ 2008/10/27_a_prop\%C3\%B3sito_de_un_arte_h\%C3\%ADbrido_o_intercultural.html

Facuse, Marisol (2008). Utopies sur scène: Le monde de l'oeuvre de la Compagnie Jolie Môme. Pratique artistique et imaginaire d'une compagnie de théâtre militant. Tesis doctoral en Sociología, Université Pierre Mendès-France, Grenoble II.

Geertz, Clifford (1992). La interpretación de las culturas. México: Gedisa.

Huesca, Helio (2009). La décima. Poesía y música popular cantada en México. México: Ediciones del Programa de Desarrollo Cultural de la Huasteca.

Laplantine, François y Nouss, Alexis (2007). Mestizajes. De Archimboldo a Zombi. Buenos Aires, Argentina: FCE.

(2008). Le métissage. París, Francia: Téraèdre. 
Lenz, Rodolfo (2003). Sobre la poesía popular impresa de Santiago de Chile. Siglo XIX, Santiago de Chile: Ediciones del Centro Cultural España (1ª ed. 1919).

Salinas, Maximiliano (2005). Canto a lo divino y religión popular en Chile hacia 1900. Santiago de Chile: Lom.

Sitografía

http://proyecto-oralitura.blogspot.com 